\title{
Back to Basics: Does Seed Size Affect Germination and Plant Uniformity in Broccoli (Brassica Oleracea var Italica)? ${ }^{\dagger}$
}

\author{
Celia van Sprang * and Gayathri Rajagopal \\ Department of Agriculture and Fisheries, Gatton, Queensland 4343, Australia; \\ Gayathri.Rajagopal@daf.qld.gov.au \\ * Correspondence: Celia.vanSprang@daf.qld.gov.au \\ + Presented at the third International Tropical Agriculture Conference (TROPAG 2019), Brisbane, Australia, \\ 11-13 November 2019.
}

Published: 7 April 2020

\begin{abstract}
Hand harvested crops, such as brassicas and lettuce, are prone to high levels of variability during growth and at harvest. This necessitates multiple harvest passes and substantially increased labour costs for the grower. Both biotic and abiotic factors contribute to this lack of field uniformity. The main objective was to evaluate the impact of broccoli (Brassica oleracea var. Italica) seed size variability on germination, subsequent crop growth and harvest uniformity. An initial experiment was conducted where germination counts across three seed-size categories including, 2.0mm (SS1), $2.3 \mathrm{~mm}$ (SS2) and $2.45 \mathrm{~mm}$ (SS3), were recorded at 3, 7, 10 and 14 days after sowing (DAS). At 14 DAS, germination was greater in the SS1 $(95 \%)$ and SS2 $(91 \%)$ than the SS3 $(66 \%)(P<0.005)$. A second experiment evaluated the same seed categories planted under direct seeded (DS) and transplanted (TR) conditions to identify differences in crop growth and development. At 49 DAS, DS plant counts per plot were lowest for the SS3 (54.5 plants plot $\left.{ }^{-1}\right)$ compared with the SS1 (70.5 plants plot $\left.{ }^{-1}\right)$ and SS2 (64 plants plot $\left.^{-1}\right)$. This could be attributed to the reduced seed coat thickness evident in the SS3 $(66.3 \mu \mathrm{m})$ which can potentially lead to increased damage and mortality of the seed, compared with the SS1 $(79.3 \mu \mathrm{m})$ and SS2 $(73.1 \mu \mathrm{m})$. The TR treatment gave greater uniformity with no significant difference $(P<0.05)$ in plant populations across seed size categories $(\mathrm{SS} 1=95$, SS2 $=90$ and SS3 $=96$ plants plot $\left.^{-1}\right)$.
\end{abstract}

Keywords: broccoli; germination; seed size; Uniformity; harvest

Conflicts of Interest: The authors declare no conflict of interest.

(C) 2020 by the authors. Licensee MDPI, Basel, Switzerland. This article is an open access article distributed under the terms and conditions of the Creative Commons Attribution (CC BY) license (http://creativecommons.org/licenses/by/4.0/). 